Review

\title{
Sustainability between Necessity, Contingency and Impossibility
}

\section{Karl Bruckmeier}

School of Global Studies, Gothenburg University, Box 700, Gothenburg, SE-40530, Sweden; E-Mail: karl.bruckmeier@globalstudies.gu.se; Tel.: +46-31-7684-4940; Fax: +46-31-786-4933

Received: 3 November 2009 / Accepted: 7 December 2009 / Published: 16 December 2009

\begin{abstract}
Sustainable use of natural resources seems necessary to maintain functions and services of eco- and social systems in the long run. Efforts in policy and science for sustainable development have shown the splintering of local, national and global strategies. Sustainability becomes contingent and insecure with the actors' conflicting knowledge, interests and aims, and seems even impossible through the "rebound"-effect. To make short and long term requirements of sustainability coherent requires critical, comparative and theoretical analysis of the problems met. For this purpose important concepts and theories are discussed in this review of recent interdisciplinary literature about resource management.
\end{abstract}

Keywords: sustainability; sustainable development; natural resource management; nature-society interrelations; interdisciplinary frameworks; transdisciplinarity; ecological distribution conflicts; rebound effect

\section{Introduction}

"Sustainable futures are ones in which the basic means of human livelihood get easier, human opportunities become richer, and nature's diversity is more sustained — and not only in the rich parts of the world." [1].

In this article knowledge problems related to sustainability are reviewed in an interdisciplinary perspective. The question guiding the review can be formulated as follows: What kinds of knowledge, which concepts, theories, methods and research results are adequate to analyse and solve the multiple problems in the process called sustainable development? In the review priority is given to scientific publications on the environment and resource use after the turn of the millennium, when the global debate in science and policy had resulted in a mainstream approach of social, economic and 
environmental sustainability. Since then the debate about interdisciplinary perspectives for research and resource management has intensified [2,3]. The focus is laid on publications that contribute to theoretical reflection and synthesis of knowledge, but no systematic overview of the research about sustainability is intended. Publications as e.g., the Encyclopedia for Life Support Systems, Encyclopedia of Alternative Energy and Sustainable Living, Encyclopedia of Earth, or more disciplinary specific ones as the International Encyclopedia of the Social and Behavioural Sciences are not reviewed.

With the intensifying interdisciplinary research the time has ended when simple definitions of environmental sustainability as living within the limitations of the biophysical environment were sufficient and the debate could be summarised as: the paths toward sustainability differ in each country or sector, but the goals remain constant [4]. The dominant problem for Goodland was immense time pressure to provide food and shelter for ten billion people within less than two generations without damaging the environment.

The differentiation between social, economic and environmental sustainability is not a more exact definition, only a heuristic device to support interdisciplinary and pluralistic approaches to deal better with complexity of systems and problems. Sustainability cannot be defined exactly-it implies unpredictable changes, surprises, hazards, innovations; for Holling it is a continued game of maintaining adaptive capability [1]. The useless efforts to clarify the problems to be met through improved general definitions [5] have probably ended, although this must not end in disillusionment as in the plea for a temporary stop of the debate to take up the search for sustainable development later on again with better chances [6], an expression of confusion about the discourse and the process. In searching for the future of sustainable development conceptual templates seem more helpful than new definitions [7]. They bring classifications of more specific concepts that allow interdisciplinary, contextualized and problem focused analyses to dealing with the challenges of sustainable development that are to a large degree insufficiently reflected knowledge problems.

\section{Problems with Sustainability of Ecosystems and Social Systems}

From an ecological perspective sustainable utilization of natural resources is a requirement to maintain ecosystem functions and services as well as a functioning global economy and society in the long run, to continue producing life support for a growing human population over generations. Efforts in science, policy and resource management to formulate and implement strategies for sustainable development since the early 1990s have shown the splintering of the guiding idea into local, national and global strategies where actors with contradictory and conflicting knowledge practices, interests and aims are involved. From a social perspective it remains unclear, which social actors are required with what activities to make sustainable development possible in national or global strategies like "Agenda 21". The widespread idea to include many actors and resource user groups in participatory and locally rooted approaches is an expression of a knowledge dilemma. Too much knowledge to be managed in strategies for sustainable resource management makes knowledge selection a main problem. There is no single discipline or subject area to deliver the knowledge required, but continually different knowledge components need to be negotiated. Evaluating the effectiveness of participatory research and development strategies [8,9] is also not an easy solution as the situations 
given vary so strongly in spatial and temporal parameters, as in the social contexts of action that it seems impossible to verify or falsify standardised solutions.

Participatory strategies imply the question: which, whose knowledge counts? Asking for actors and their knowledge makes visible controversies about the preconditions for and the implementation of strategies for sustainable development: e.g., about weak and strong, technocentric and ecocentric strategies with further subdivisions [10]. The requirements for integrating economy and ecology remain rather unclear beyond that for multilevel frameworks and the cautious approaching of a core problem, international redistribution of resources, under the diplomatic formula of "international sharing of responsibilities" [11]. A more critical debate about unequal conditions of sustainable development in the global context [12] has generated valuable insights, deepening the discussion about transition to sustainability under the different economic and social conditions in the countries of the global North and South. Whether separate and isolated urban, regional or national strategies are possible in the situation of global interaction at social and ecosystem levels is also a practically relevant question - see the controversies about the "de-materialization myth" [13,14], "ecological distribution conflicts" [15], "rich country illusion effect" [16]. All these phenomena relate to sustainable development in the modern world system where industrialized countries protect the environment and the natural resources in their own territories but continue their environmentally destructive resource imports from less developed countries in the South. The rebound effect [17] describing unintended consequences of improved technical efficiency of energy delivery in form of increased consumption, thus annihilating efforts of energy saving, adds up to the difficulties in achieving sustainable resource use practices. Sustainability seems too encompassing an idea that carries too many unsolved problems of the past - poverty and population growth, human wellbeing and economic growth, industrialisation and its unintended consequences, environmental destruction and climate change, finite resources and distribution of resources, a disembedded globalising economy and a modern world system that is limited in its capacity for adaptive change. Whether all these problems come closer to solution by putting them in one formula of sustainable development may be doubted.

The problems and controversial debates sketched above would still be misjudged with a quick conclusion - that sustainability is impossible, because of its vague and contested conceptual nature, or because of the complexity of the problems to be solved and the changes in social and economic structures or individual behaviour required. The problems to deal with under the notion of sustainable development require new ways of understanding complex problems in science, policies and technologies. This showed e.g., the "post-normal science" — or "transdisciplinarity"-debates (see below), or demands for re-integration of social symbolic and material reality [18] in analyzing complex adaptive processes [19,20]. Such new social practice of knowledge use is required for interacting social and natural systems with conflicting aims and requirements, in policies or resource management strategies. The critical analysis of prior research about resource management problems shows that expectations to find standardized or "panacea"-solutions, with principles that work in heterogeneous contexts and circumstances, have been unrealistic, should be given up in favour of networked but diverse, locally adapted solutions (Ostrom, see below). In policy processes the idea of sustainable development is dealt with as discourse platform or bridge concept where always a variety of scientific and political actors and interest groups are involved in the discourses; where there will be 
a constant requirement of integrating heterogeneous knowledge and interests; where there will be changes in actor constellations and knowledge over time [21]. Further requirements for continually adapting and improving the ideas about sustainability can be developed by identifying knowledge forms and practices to deal with situations of complex problems, badly defined situations, incompatible knowledge and interests, multiple and varying socio-cultural and ecological contexts.

A conventional answer to deal with the complexity described would be "reduction of complexity". Practically this does not help much; the question "how to reduce complexity, which knowledge practices and strategies are adequate in a given situation?" comes up in every step of selecting and reducing the knowledge applied again. Solution formulas as that of "requisite variety" in the reduction strategy also do not seem to provide safe methodological orientation. And whether the philosophy of systems thinking, post normal science and transdisciplinarity - to look for less perfect, "bounded", or "robust" solutions-will generate lasting solutions for sustainable development is still an open question. Sustainability is not yet an impossible future because of its complexity, but it becomes contingent; it remains open whether, how, in what time it can be achieved. It can be pursued in various ways, seems possible in certain aspects and to certain degree, but never definitely achieved [22]. Given the impossibility to define and operationalize sustainability in universal ways, solution ideas require thorough investigations of the spatial and temporal scale problems and conflicts to deal with in sustainable development. The temporal dimension seems decisive in sustainable development of complex systems under varying contexts [23]. It requires ideas for long-term processes in a time perspective of several generations and for the matching of short and long term requirements in the development of ecological and social systems.

The difficulties that come up in the transition to sustainability include that of knowledge production by positioned researchers and actors, with partial perspectives, in different cultural contexts, as formulated earlier e.g., in the idea of "situated knowledge" [24]. Turbulent situations or unforeseen changes that come with global environmental change, especially climate change, add up to the impossibility of universal and panacea solutions. However, more important than context sensitivity in knowledge practices with the subsequent problem of heterogeneity of practices and institutional diversity $[25,26]$ are the neglected and unsolved problems of global distribution and consumption of resources [27,28]. These ask for a new political economy of global resource use with analyses of unequal exchange and redistribution of resources in the global economy. Such unsolved problems may give rise to the assumption that sustainability is impossible, with progress through technical improvements or in some areas annihilated through ongoing growth, overuse and pollution in others or by other resource users as has become evident already (see "rebound"-effect and "rich country illusion effect"). Sustainability seems to be overrun by economic globalization and gradually transformed through other concepts that signal urgent or short-term necessities of action, e.g., preparing for the effects of climate change in reducing the vulnerability and enhancing resilience of social-ecological systems. Whether the short and long term requirements of sustainability and of sustainability and resilience can be successfully matched requires more critical, comparative and theoretical analysis of the problems; reflection on the abstract and contested nature of such generic notions as sustainability and resilience; and an analysis of the global economic system in its historical specificity, its limits, its consequences for humans and for the environment. Such global political economy has since the seminal book of Polanyi [29] developed under the formula of dis-embedding and re-embedding market 
institutions, or bringing the economy under social, political, cultural control again after a long and still accelerating trend towards deregulation [30]. Sustainable development requires further discussion of such ideas and of the notion of scarcity. Scarcity in the specific form of a market based mechanism, an institutional invention in the modern market economy, differs from ecological scarcity of natural resources as natural condition linked to ecosystem productivity but not to pricing as distribution mechanism. Scarcity did not need to be differentiated into natural and institutionalized scarcity as long as market mechanisms were not dominant in economic production, e.g., in agricultural societies, and natural scarcity was still the main barrier of production improvements that could only to a limited degree be removed by slow improvements of agricultural production technologies. In the sustainability debate today it is necessary to become aware of both forms of scarcity, natural and monetary, to identify appropriate institutions for the distribution and utilization of natural resources.

Polanyi diagnosed that disembedded economies tend to destroy their resource base in the long run. They extend resource use beyond the limits of local availability of material and energy resources, through trade and exchange, without taking into account effects of that in the areas from where resources are taken. To analyse this further requires concepts and theories from interdisciplinary research about resource management: analysis of social-ecological systems and social-ecologicalepistemological systems [31]; of common pool resources management, integrated measurement and assessment of matter and energy flows; of unequal resource flows in the global exchange and trade, with knowledge practices that may help to approach sustainability in a global context of socioecological system development. The knowledge processes will be in focus here-which concepts, theories, methods, research results can be used to deal with the multiple problems in sustainability discourses and policies?

Using abstract, fuzzy and de-contextualized notions such as that of sustainability itself or of resilience, and the formal notions of necessity, contingency, impossibility seems to be part of the problem that a non-controversial diagnosis of problems to be dealt with on the way towards sustainability cannot be expected. It is not possible to define sustainability in a general and universal form, except as trivial tautology - e.g., sustainable is what exists for a long time, although in the still much shorter dimensions of societal, not geological time. Sustainability at local levels is affected by heterogeneous factors, properties and structures of ecosystems, social systems and knowledge systems. Whereas the critical reflection on the multifaceted idea of sustainability is part of the discussion following here, the formal terms of necessity, contingency and impossibility cannot be specified. They remain abstract concepts that cannot be easily replaced. They too may be understood in different ways and require critical reflection [32] although originating from disciplines, philosophy and logic, that aim at clear but abstract concepts. Formal clarity or "mathematical precision" of language does not necessarily help in coming to terms with sustainability problems when the contexts of knowledge generation and application are culturally heterogeneous. But using the abstract terminology can at least help to describe a knowledge dilemma that seems to come with the term "sustainable development". Daniel summarized the history of the development concept since the $18^{\text {th }}$ century. At that time it has become a concept to describe complex dynamics of irreversible change in time which can only to limited degree be influenced by human action. It implies the assumption of a subject of development that remains identical in this process, be it an organism, an individual, a nation, and a more or less explicit assumption of goal-direct development processes. All that makes the notion of development 
one to expel, avoid, combat contingency [33], to create continuous progress and improvement, a core idea of industrialisation. But with sustainable development contingency comes back; the notion gives an example for contingency in the sense of having to cope with risks, non-deterministic and weakly structured or instable systems, plasticity of systems, unforeseeable events, lack of universally valid knowledge. To avoid being stuck in every operation in this dilemma of sustainable development as oscillating between necessity or contingency, the problems related to sustainability are discussed here at more specific levels, using the formal concepts illustratively: with regard to present natural resource use in a global context and the problems inherent in that; to interdisciplinary research about socialecological systems; to theoretical perspectives for reformulating a global political economy; to changes in the core ideas of sustainability.

\section{A New "Epistemology of Complexity" - Concepts, Theories, Perspectives for Sustainable Development}

The older epistemology of complexity drafted by Boulding [34] was rather simple with its message that complex systems are of two kinds, determined and predictable ones with stable parameters and indeterminate or partially predictable ones with changing parameters. This supported the conclusion that methods appropriate for one kind of systems may not work for the other. The argument has not become invalid, but needs to be refined, specified and completed with further knowledge. To do so, Ostrom's, Agrawal's and Acheson's [26,35,36] diagnoses are helpful: failures in resource management in complex social-ecological systems (SES) with a great diversity of context factors happen due to misguided search for standardised, universal or panacea type solutions.

The problems to deal with under the overarching terms of sustainability and sustainable development require improved knowledge practices [37] and improved institutional practices [38] to generate preliminary solutions that allow for creating solutions in the longer run. But both issues have been discussed with insufficient attention to the changing contexts of knowledge generation and political action over time. The framework constructed for systems that link knowledge to action for sustainability in sustainability science [37] with the boundary management components of communication, translation and mediation suffers from a primacy of science-hypothesis. Scientific knowledge plays a dominant role in strategies aiming at sustainability; yet to neglect other knowledge forms and orient towards communication between scientific experts as knowledge producers and decision makers as knowledge appliers prioritises conventional unidirectional knowledge transfer processes instead of knowledge and power sharing between different actors and resource user groups. On the other hand, analyses of the institutional arrangements for sustainable development-for cooperation of actors in resource regimes at local, national and global levels - also tend to neglect the wider and changing context including science and knowledge production. They are conceived of too narrowly as institutional and actor-related problems of creating social capital or cooperation under conditions of heterogeneous interests and conflicts [38,39], or in adopting a co-evolutionary perspective of systems management [40]. The reconstruction of the contexts of SES requires theoretical knowledge to formulate strategies for sustainable development which include the systemic context with the domains of (a) political, economic and cultural contexts within the societal system under consideration; (b) the ecological context, the functions and services of ecosystems and global 
environmental change. Beyond that (c) the scientific and knowledge context with regard to systems of knowledge and their limits requires attention.

Interdisciplinary knowledge is required for a global political economy of sustainable development or a political ecology [41-43] if this misleading term is meant to combine knowledge from ecology and political economy in analysing flows of energy, matter and information in coupled social-ecological systems [44]. These flows make the interacting systems complex and from them result negative social and environmental effects of a globalised economy blocking sustainable development $[19,45]$ The research about democratization and economic globalization did not show clear results of positive interaction for developing countries, therefore Milner and Mukherjee [46] asked for more theoretical research. Knowledge practices and institutional arrangements for sustainable resource management require a broadening of interdisciplinary cooperation and knowledge integration, not only across the boundaries of social and natural sciences, but across the boundaries of science to include other knowledge forms, especially local knowledge. The extension is marked with debate about "mode 2" and "transdisciplinarity" with the underlying hypothesis of a new contract or partnership between science and society [47]. Although lacking empirical proof for the claimed change in science-society interaction and not necessarily directed at natural resource management problems, this discourse touches important ongoing changes in knowledge production that become relevant for environmental sustainability, e.g., the changes in resource and knowledge commons and the privatization or "propertization" [48] of intellectual and material resources.

Analyzing socially structured knowledge practices helps to discuss the unanswered questions about sustainability of socio-ecological systems as that one: What kinds of knowledge are adequate to analyse and solve or mitigate the problems that come up in the process called sustainable development? To work with a vague general definition of knowledge from philosophy and to rely on empirical research about knowledge generation and application, as e.g., in the sociology of science or knowledge, is but a provisional answer. Science studies [49] and cultural-anthropological analyses of science [50] have shown the multiperspectival and multicultural character of science, devaluating a universalistic epistemology for scientific knowledge production. Luhmann discusses changes in scientific knowledge production, concluding that it proceeds rather by particularization than by generalization-occasionally, incrementally, with interruptions, taking into account that new knowledge co-produces also new ignorance, a situation which he describes borrowing Mertons' notion of "organized scepticism" in knowledge production [51]. Similar discomfort results from the postmodernist discourse with the renouncing of "grand narratives" among which universal theories are counted, from the concept of situated knowledge taking into account the cultural practices of knowledge producers and their traditions of knowledge production [24], and from the discourse about social constructionism; for its consequences for environmental research see [52-55], for the differences between the approaches [56]. All these discourses restrict the idea of universal concepts, explanations, knowledge, although not always with the same arguments and intentions. To deal with the "AntiTheoretical Fin de Siécle" [57] Boron argues for a deepening of historical analysis instead of too quickly neglecting history and borrowing natural-scientific frameworks as chaos theory for the analysis of modern societies. Stehr [58] searches a way out of the epistemic crisis with ideas such as "knowledge politics" or knowledge governance to formulate a preliminary overarching idea, one of knowledge negotiation, not epistemological and methodological rules. 
Trying to bring such contingent forms of knowledge generation and synthesis into the transdisciplinarity and sustainability discourses, the above question "whose, which knowledge counts?" comes up again as one of plurality or pluralism of concepts and frameworks [59] and of ageing or outdating of knowledge, a mechanism in the validation of scientific knowledge that seems less effective the more knowledge, competing research results and interpretations are available.

With both issues social criteria of knowledge use come into view. Discussing accepted frameworks and explanations and deciding about the knowledge accepted among a plurality of competing data and varying interpretations is hardly guided by methodological criteria (for the complex and paradoxical components of interpretation see [60]). Easier than in conventional academic research the negotiation processes can be seen in interdisciplinary discourses in the Intergovernmental Panel for Climate Change, in the Millennium Ecosystem Assessment, or in the world agriculture report (IAASTD) where science becomes policy and the knowledge negotiation processes are manifest. It may appear amazing that in core areas of sustainability research as the ones just mentioned there has emerged scientific pluralism with open knowledge negotiation controversies and practices. The new "post normal science" is more a provisional practice, a new "science of muddling through", where power fights between experts go on, controversies about definition power. Not everything is open to negotiation, as lasting difficulties to integrate social-scientific and natural-scientific knowledge have shown, early in the sustainability discourse articulated by Redclift [61]. In the social structuring of knowledge production and application the existing components of scientific knowledge are still required-theorems and theories, epistemologies and methodologies, paradigms and research programs, methods and verification criteria, and moreover new methods for integration and synthesis of knowledge. Whereas methods, production of data, interpretation processes and part of the normative assumptions guiding interdisciplinary research are reflected, others are rather neglected in the sustainability related discourses, among these (a) the key concepts themselves, (b) theories and conceptual frameworks, and (c) knowledge perspectives for analysing sustainable development in interdisciplinary approaches. These points are discussed further before the concluding reflection about (d) new methodologies to address the complexity of sustainable development.

\subsection{Key Concepts}

Sustainability and sustainable development as framing ideas of a global discourse are not necessarily key concepts that need further clarification. Whether they should be seen as concepts in the strict sense of the term is doubtful; they served in the discourse hitherto more as guiding ideas, discourse platforms or bridging concepts that can be revised and reinterpreted continually between experts and actors. As a consequence of the vagueness, of different and changing interpretations of the guiding terms, clarity is more important at other levels of the debate, in descriptive and operative discourses where knowledge about system properties, transformation of systems and actors is used more important, as e.g., in strategies of environmental governance [62]. Formulation of threshold levels or state descriptions for achieving sustainability, elaboration of indicators or indices for measuring progress (see below), and specification of the critical concepts to analyse the complexity of systems in the process - the hitherto vaguely conceived social systems, ecosystems and their 
interaction or social-ecological systems - are among the components requiring further clarification, as well as the resilience concept.

The definition of sustainability will be less problematic when one can interpret and specify the guiding idea through further concepts or insights that affect the spatial and temporal scales and parameters of sustainable development. This happens e.g., with the resilience research and debate [1,63-65], indicating that the notions of sustainability and sustainable development have become contingent with the interdisciplinary opening and broadening of the discourse. Discussing "resilience and sustainable development" has not yet produced many lessons for sustainable development policy [66]. The debate goes on in a period of paradigm change in ecology [67], with the resilience concept bearing meanings from different times and paradigms: the older idea of equilibrium and climax dynamics of ecosystems that support a notion of resilience as maintaining stability (engineering resilience) and the newer idea of instability in ecosystems, without equilibrium, that supports a view of resilience as meaning to sustain a system also under unforeseen, rapid and disruptive changes [68]. Diagnosing a paradigm change in ecology seems only half true: both the equilibrium and the non-equilibrium paradigms are further on used by many ecologists [44]. To connect resilience and sustainability [69] could be expected when the paradox of short-term efficiency and long-term sustainability of resource use was discussed for which the concepts of resilience and institutional flexibility should help to formulate solutions [63]. But it required further catalysing processes such as the climate change debate and accompanying natural hazards [70] before this connection became important. Still Perrings [66] summarizes only few results, one from ecology-that diversity of systems is an indicator of resilience and sustainability. He sees conflicts between long-term resilience and short-term productivity and also between resilience at different spatial scales. Such ideas can be introduced in the analysis of social-ecological systems (SES), but still the resilience concept implies such a great variety of phenomena in ecosystems and social systems that the term is not easy to handle, neither through Perrings' specification of different kinds of resilience, nor through separating social from ecological resilience conceptually [71], nor through introducing new metaphoric notions such as vulnerability in the analysis of social-ecological systems.

Within SES more specific systems analyses of coupled social and ecological systems should be elaborated. Not much has yet been gained from understanding both system types as interacting or coupled — or a normative holism that reduces sustainable development to a kind of spiritual revolution to change the dominant views of nature and world in modern societies, a longstanding and naïve idea among parts of environmental movements, resurfacing in different variants of deep ecology, spiritual feminism, religious ecology and others. There is a much longer, critical and theoretical debate about nature-society interaction from which very little has been learned except in few interested epistemic communities, e.g., in social ecology. Olsen [72] has constructed a framework including socio-ecological organization and its interaction with socio-cultural organization; he sees social ecology as an integral part of human social organization or society. By refining such analysis of interacting systems, the sustainability discourse can be pushed further, with a theoretical underpinning of vague concepts (see below), with in-depth analysis of system structures and barriers to adaptive change of the modern world system as a historically specific interaction of society and nature. 


\subsection{Theories}

Searching for theories for the sustainability discourse may start from the social sciences [42,73,74] and philosophy of nature [75] where the theory debate is more intensive, although it is not necessarily a sociological or philosophical theory that is sought, rather interdisciplinary frameworks of combined theories. So far inspection and review of theories in natural and social sciences has been a neglected part of sustainability research, beyond ad-hoc constructions of frameworks like that of pressure-stateresponses [76]. Elementary attempts as that of Szostak [77] to classify relevant theories end with a summary of the difficulties in clarifying the theory concept inside the boundaries of social sciences and applying it in boundary crossing research. As a step towards further theoretical reflection and synthesis of knowledge Little [78] has reviewed research trends in anthropology, taking up many of the conceptual components reappearing in the later unfolding interdisciplinary and theoretical discourses - different levels and scales of analysis, historical analysis, spatial analysis, environmental discourses, movements and rights.

General theories in the social sciences after the end of so-called "grand theory" include that of risk society $[79,80]$, the related one of reflexive modernization [81], more interdisciplinary actor-network theory $[82,83]$ or globalization theories [45,84]. The specific discourse of ecological modernization [85] is limited to certain social and power aspects of sustainable development. It provides a contested theoretical model for sustainable development derived from the industrialized global North which works less for the counties in the South, and does in its earlier versions not take into account global resource flows in a systematic way (only more recently it was connected with the flow paradigm in sociology which can be seen as approaching an analysis of global flows of energy, matter and information). None of these theories seems to deliver sufficient, historically specific analyses of interacting social-ecological systems at global level although all of them are close to environmental and sustainability issues. Main reasons for their limited value may be their high levels of conceptual abstractness or specialization; their abstract and decontextialised concepts such as risk, modernization and modernity; their conventional "mode 1"-manner of reflection and arguing, as part of specialized academic science. Only the two discourses of actor network theory (also discussing interaction between humans and nonhumans) and globalisation are more open for interdisciplinary knowledge transfer. What would be required in the sustainability discourse are in-depth theoretical analyses of changes in different societies and their resource use practices as can be found more outside the academic mainstream, in research about common pool resources (Ostrom and others), although not linked to global flow analysis, and the social-ecological research about sustainability.

In social-ecological research unfolding in the past decade especially in Europe only two macroscopic theories as theories in the sense of systematic analyses and partial explanations for the changes of modern societal systems in a global context have been discussed: (a) The world system theory by Wallerstein and others [86], not a new theory, but one influencing socio-ecological research through research in environmental history [87], complementary to the long-term historical perspective of human- and landscape-centred historical ecology [88]; (b) a so far unfinished renewal of a critical theory of nature-society interaction for present societies under the heading of social ecology.

An early example of such an interdisciplinary theory of nature-society interaction [89] is hardly discussed in the present discourse. The social-ecological theory in progress develops along more 
social-scientific variants [90] and more ecological, natural-scientific variants [91,92] These theories differ in origins and disciplinary roots, but not so much in their basic arguments, including the necessity to specify the historical development paths and system qualities to go beyond a vague notion of modern or Western societies, e.g., with the help of the concept of socio-ecological regimes. The conclusion has been formulated rather early that sustainable development policies "of industrial societies should focus on strategies to reduce material and energy turnover" [93]. For some time, in connection with the postmodernism discourse, the deadlock argument was tried to parcel theory in divergent and incompatible microscopic theories of local resource use practices [44] but the re-strengthening of the theories mentioned above indicates that only combining macroscopic and microscopic theories can help, or the analysis of global resource flows will be neglected. The theories of society-nature interaction referred can be linked with more specific theories of global governance $[62,94]$ to formulate new regulatory strategies for sustainable development. But the question remains, why is the discourse about sustainability science not included as an emerging interdisciplinary framework of analysis? It is because of its unclear implications about theory and its vague idea about nature-society interaction that does not allow for a specific theoretical account of the system properties of present societies under globalization. There remain three theoretical discourses that can be connected:

World system theory is known as a critical analysis of the unequal exchange, including distribution conflicts between the global North and South. But it has been widely overlooked that this discourse is more than others focused on analysis of global material and energy flows as constituents of modern social-ecological systems, information relevant for sustainable development programs that ecologists and ecological economists have demanded for a long time. A more elaborate analysis of these flows is presently under development in the social-ecological theories in progress.

Social-ecological theories of nature-society interaction have renewed the older problem formula of "societal relations to nature" in the tradition of critical theory, but with new, more interdisciplinary and resource-related concepts such as societal metabolism, colonization of nature, social-ecological regimes [92]. With such concepts the long existing gaps between social scientific theories and ecological research seem to be reduced, mainly through their operationalization in terms of matter and energy flow accounting or calculation of human appropriation of ecological primary production.

"Critical change"-theory: It seems more difficult to identify theoretical concepts and frameworks from ecology that can be linked with social-scientific frameworks to improve analyses and strategies for sustainable development. "Adaptive management" with critical assessment of former resource management approaches [95] can hardly be called a theory of nature-society interaction, at best an operative managerial component of that. Specialized theories to describe the dynamics of specific ecosystem types, e.g., landscape, forest or marine ecosystems, cannot support the knowledge integration either, as also specialized sociological theories of the "ecological modernization" type (see above). But attention to different spatial and temporal scales in ecosystems is important. For theoretical reflection of such dynamics the changes in threshold behaviour with resilience as a core component seem of major interest for an interdisciplinary reconstruction of development trajectories of linked social-ecological systems. A theory of catastrophic change develops from conceptual elements of threshold behaviour and patchiness of ecosystems, linked through the concept of "criticality" derived from statistical mechanics $[63,96]$. The "critical change"-debate is at the crossroads of several 
important discourses related to the dynamics of social and ecological systems which can all be seen as parts of an analysis of facets of contingency in the sustainability processes - "emergent properties", "resilience", unforeseeable events, behaviour and interaction of actors over distance; local context changes influencing changes of systems at larger scales - all important for both social and ecosystems. Variants for critical change of systems and their spatial and temporal determinants can be expected to be formulated more exactly with that theoretical framework, thus meeting such requirements of sustainable development as: to find various strategies for adaptive change in comparing complex systems [97], knowing better what the consequences of societal risk strategies are [39], knowing when coupled social-ecological systems can continue their development paths after disturbing events without changing parameters, when disturbance causes changes of parameters or when there is a risk of system collapse.

Concluding important insights from the theories mentioned for further analysis of sustainability and sustainable development, the following arguments seem of relevance, arguing for a combination of several theory components:

Using world system theory to provide a theoretical description of the historically varying systems of society and economy, the core argument is that of a modern societal world system as a system at several levels of organization with incoherent principles of structuring: it is globally coordinated only as an economic system, but not as a political system, and not as a cultural system - there is a dominant culture, that of the West, but not a universal one. The division in core and periphery functions is only modified within globalisation, reproducing unequal development of countries or regions with differences as the older ones between industrial- and developing countries in new forms. With more specific socio-ecological regime descriptions in the present unclear overlay of different development strategies in different global regions-"post-industrialism", "late industrialisation" and "extractive economies" - critical issues of unequal exchange and resource transfer between the global North and South come into view. The core issue for global sustainable development becomes international redistribution of resources, requiring solution of ecological distribution conflicts according to ethically justified principles as solidarity, equity, sufficiency (with more precise criteria for the Brundtland-term of "inter-generational equity").

The dynamic interaction between society and nature, theoretically conceived of as material and symbolic interaction in historically specific "societal relations to nature", draws attention to a critical issue and deficit in SES and sustainability science. To neglect the analysis of distinct system properties and historical development paths of modern societies, e.g., through physical or biological reductionism, analysing societal systems in terms of natural systems, is also to lose relevant information about the unequal resource flows in the global economic system that cause much of the non-sustainability of industrial economies (for the critical argument see Becker, E., ISOE, Frankfurt am Main, discussion paper 28, 2006: online: http://www.isoe.de/ftp/EB_gegen_verwischen.pdf).

Anti-reductionist versions of nature-society theories in ecological variants are formulated in exemplary ways by $[91,92]$, focussing on the processes of societal metabolism or physical interactions between human societies and their natural environments. In this discourse historically specific approaches to describe societies (Boyden, Godelier, Sieferle) are used, although somewhat different from world system theory. Here a main argument is that of the different scales and temporality of cultural and ecological evolution that requires further and more specific linking mechanisms than 
provided by world system analysis, e.g., detailed analysis of social-ecological regimes to identify transition paths towards sustainability.

The ecological research and emerging theory about criticality of ecological systems has yielded as a first important step of theoretical codification and reflection a typology of three forms of criticality in ecosystems opening up new directions for resilience and its interaction with sustainability [96]: criticality resulting in shift of system state (well mixed disturbance and distributed disturbance with different time scales) and avoiding shift of state (distributed disturbance with recovery). To introduce these concepts into the analysis of coupled social-ecological systems (not only ecosystems) would help to develop the theoretical analysis of disturbance, catastrophic change and their consequences for long-term development processes.

\subsection{Perspectives and Knowledge Practices}

Theoretical reflection on knowledge generation in social practices of science and resource management has not progressed far, despite an intensive dialogue about interdisciplinarity, "mode 2", "transdisciplinarity" [98] and the "triple helix" of knowledge production in cooperation of universities, governmental institutions and private companies since the mid-1990s. Limited progress is found when it comes to questions of linking this knowledge discussion with social-scientific and ecological knowledge about the evolution of societal and ecosystems. Longinos' ideas mark an important step away from formal epistemologies to account for generation and development of knowledge in socially structured processes, but the results in terms of a theoretical synthesis of knowledge processes remain vague, as also the ideas about scientific or explanatory pluralism [99] that may be relevant for inter-disciplinary theorizing about nature-society interaction. The other interdisciplinary debates mentioned have not come further. Controversies between the transdisciplinarity-authors [47] and the "triple helix"-authors [100] reveal some inherent weaknesses of both attempts to analyse the changes in science-society interaction: they lack a specified theory of society after the diagnosed end of "classical modernism" and cannot replace such theories for social-ecological systems analysis as summarised above. The transdisciplinarity authors do not adopt the postmodernist discourse, but share part of that diagnosis of culture-related change in modern societies as part of their own description. Nowotny and co-authors [47] criticise also the concepts of knowledge society and of risk society for their simplicity and implicit orientation to science and technology, claiming that risks in present society are more the consequence of success of science not of failure or ignorance. But they do not come up with their own theory about the transformation of modern society beyond their description of changing practices of knowledge production. The triple helix debate refrains from theory in empirical studies of knowledge coalitions with just vague reference to a "neo-differentiation"-hypothesis for societal development, renewing older ideas from social systems theory [100].

The theoretical debates about changes of modern societies allow for the conclusion, that these debates have been "overheated". More than theoretically conceptualising changes they indicate difficulties to understand the processes ongoing. Nothing more but a somewhat specific modernity and ongoing modernization can be diagnosed with a sociological theory of postmodernity [101], similar to Becks' risk society description, and not very satisfying knowledge to address global problems of sustainable development. As the authors in the new knowledge and theory debate are mostly from 
social sciences and humanities, it seems there is an inherent limit and bias in their analyses regarding knowledge about ecological systems to understand better how societal structures affect ecosystems and their changes. But there are hardly any ecological authors either who take up such questions, beyond the rudimentary premise that ecosystems also include humans and in spite of a growing interdisciplinarity of ecology.

With regard to these deficits the "post-normal science"-hypothesis by Funtowics and Ravetz, developed in contrast to Kuhns" notion of "normal science", to account for knowledge situations where risks are high, values disputed and decisions urgently required [102-104] was rather promising and generated important insights that Ravetz compiled with regard to sustainability: uncertainty and valueloading characterize science and knowledge production, especially but not only in a context where policy enters into production and application of knowledge; wicked, complex problems and systems with the properties of multiple knowledge perspectives, multiple temporal and spatial scales, unexpected changes prevail as well as plurality and variety of styles of life, consumption, knowledge use, all these requiring reflexivity, dialogue and mutual learning in knowledge production, avoiding the misleading assumption that scientific experts with their abstract and general knowledge have the superior and valid knowledge, thus devaluating local knowledge, an argument that lead to asking for extended peer review, opening the assessment of knowledge to include more groups of knowledge bearers, not only scientific experts [105].

From his account of knowledge production in post-normal science Ravetz derived preliminary components of strategies for sustainable development that include knowledge integration, attempts to understand the emerging knowledge based society, new models of governance, new ethically based principles for interventions in ecosystems (such as the precautionary principle), inclusion of paradoxes in the analysis of complex problems (also changing views of the world), building foresight studies on the exploration of possible consequences of present tensions and conflicts instead of constructing only wanted futures in idealized scenarios. These ideas seem to summarize some basic and still valid principles for knowledge production for sustainable development-not substantially differing from ideas about "adaptive management", "navigating social-ecological systems", sustainability science and SES. But it will be decisive how these basic ideas are refined, completed, integrated and modified in interaction with ongoing social-ecological research.

The above discussion of concepts and discourses in relation to sustainability implies an indirect answer to the question why more popular critical debates in the sustainability discourse are not taken up here: e.g., that sustainable development is a misguided idea; an ideology of the industrialized North spread with the help of scientific theories as that of ecological modernisation; has hidden agendas; is based on fictitious consensual or win-win-thinking and avoids discussion of critical issues such as ecological distribution conflicts and unequal exchange; lacks ethical justification; uses doubtful and vague universal diagnoses such as that of a spiritual crisis of modernity; or is hopelessly torn in controversies between irreconcilable interpretations of the guiding ideas. Such critical and polemic debates contribute partial insights or partial truths. Parts of their arguments can be reformulated within the theoretical perspectives discussed here-hopefully in more convincing forms. The polemic forms of reasoning seem to try to stop the debate before it has had a chance to prove as meaningful, with the assumption: As soon as one accepts to discuss about sustainability or sustainable development one needs to have a specific (positive) view on that as meaningful idea, and this precludes to become aware 
of that the idea is wrong, misleading, ideology or the like. Such reasoning seems to echo attitudes prevailing in older science wars, pointing out the puzzles and paradoxes that are implied in a concept, approach or position to show that it cannot be maintained.

\subsection{New Methodologies to Address the Complexity of Sustainable Development}

Social-ecological research as discussed here has strengthened theoretical reflection, but even more consciousness of the knowledge processes, methods and practices in sustainability research. With the discussion of methodologies for sustainable development one completes the theoretical discourses from which some important methods have been developed. Methodological debates about indicators for sustainable development happened in recent years in the discourse of ecological economics, starting with the valuation of natural resources [106] and related discourses where sustainability indices are discussed for "measuring the immeasurable" [107]. Knowledge problems in focus are to provide sufficient information and data about sustainable resource use, consumption or wellbeing at different levels of aggregation, from the individual consumer, household, city, region, nation to the global population.

The ecological shadows of consumption [28] in terms of consequences for environment and health, ecosystems and lifestyles are discussed with the elaboration of indicators for sustainable development [108]. From the important indicators for natural resource use-ecological footprints [109,110], material and energy flow accounting [111,112], human appropriation of net primary production of ecosystems [113], the complex human development index [114], and the still more complex environmental sustainability index [115] — one may derive the conclusion that there is already substantial global over-consumption and social inequality of resource use. That this cannot go on for unlimited time without destroying the global resource base implies arguing for reducing consumption and national and global redistribution of resources. The attempts to answer the question "what levels of resource consumption are compatible with sustainability of social-ecological systems?" are mainly derived from calculation, assessment or modelling of material resource flows in economic processes of production, distribution and consumption, but do not include sufficiently the social complexity of resource use processes that is mainly one of social differentiation and of social distribution patterns. For a more complete discussion of progress in sustainable development two main types of indicators need to be combined because of their complementary information, (a) about the ecological components of human well being (matter and energy use, degradation of ecosystems [109-113,115] and (b) about the social components of human wellbeing [115]. All these sustainability indicators require large quantities of data but are still limited-presently an index measuring sustainability in all dimensions is not available and cannot be expected soon. No more simple indicators as income or standard of living can be used in the sustainability discourse, only combinations of objective and subjective indicators as in the human development index. But the expectation to develop less complex indicators may still not be given up.

The development of indicators results in similar knowledge practices to that supported by the concepts and theories discussed above: to seek adequate knowledge for sustainable development through less abstract and universal terms [116]. That the indicators can inform and rationalize the discussion about approaching sustainable levels of resource use is not to be doubted. But still they 
have a knowledge bias with their preference for data collected through science and research, only opening a small window to other knowledge forms, by way of using some subjective indicators, but not systematically integrating scientific and non-scientific, local and practical knowledge. Indicators for that are presently at best available in very simple forms, e.g., the (participatory) organization of research and decision making processes.

\section{Discussion and Conclusions - Knowledge Processes for Sustainable Development}

Dealing with complexity: The philosophical terminology of necessity, impossibility and contingency which framed the problems to be dealt with in the sustainability discourse allowed for critical discussion of concepts, frameworks and methods that need continual improvements with the development of knowledge in social-ecological systems research. To go beyond formal epistemology and approaching more concrete knowledge practices in sustainable development research and practice was intended in this review. The nature of abstract and formal concepts needs to be discussed critically, including also knowledge related concepts such as the terms of concept, proposition, truth, judgement, verification and others [32,117] to deal with the scientific problems of objectivity, ideology, constructivism and realism in knowledge generation and utilization. For dissolving abstract knowledge discourses into analyses of socially structured knowledge practices the debates about situated knowledge, "mode 2" and transdisciplinarity helped in opening other paths for knowledge development. Systematically accounting for social structuring of knowledge processes, not for cognitive structuring only as in traditional epistemologies, supports interdisciplinary synthesis of empirical and theoretical knowledge. Uncertainty, risks, limits of knowledge and ignorance appear less as dangerous weaknesses of science, can be dealt with in inter- and transdisciplinary approaches of sustainability research that imply navigation of ignorance [118] as e.g., strategies of adaptive management. It seems that the combination of normative, empirical and theoretical knowledge is a critical point, but not an argument for "anything goes" or a normative holism to bring back scientific knowledge under the guidance of a dominant philosophy or worldview. How critical and reflective practices of knowledge integration with empirical, normative and theoretical knowledge components can be achieved is a key question for knowledge processes in sustainable development.

Social-ecological systems: The social-ecological research unfolding rapidly in the past decade has supported the sustainability discourse with new efforts at interdisciplinary theory, enlarging the repertoire of methods and indicators for assessing sustainable development, and with a higher consciousness and systematic reflection on knowledge processes for sustainability. This latter point includes two important practices for knowledge management:

A differentiation of knowledge forms can be developed according to different levels of the sustainability discourse (e.g., scientific, managerial, local; normative, descriptive, operative). These can be linked with different functions of knowledge - for navigating, system analysis and system transformation, or generating, integrating and transforming knowledge [90]. This allows to better approach problems at different levels of theoretical reflection and conceptual abstractness, resulting in systematic specification of concepts. It can help to integrate knowledge production and application in science and policy, not separating these spheres. 
To deal with problems of knowledge application, knowledge sharing and internal differentiation of research and knowledge production processes requires to take account for the different social functions and forms of knowledge as e.g., epistemic qualities of research (problem and actor orientation, transdisciplinarity), thematic focus of research that allows to make use of theoretical concepts and frameworks (relations or interaction between humans and their natural and social environment), and application of research for specific action and policy contexts supporting sustainable development.

Valid knowledge: Knowledge is ageing and becoming outdated, but not all knowledge relevant for sustainability becomes outdated with ageing, even not all empirical data. The difficulties to formulate new theories of society and society-nature interaction in the examples reviewed above show another problem of ageing of knowledge. Theories of modernity, modernization and industrial society are seen as outdated today, no longer sufficient to understand present global changes. However, the efforts to formulate new theories - risk society, postmodernism, transdisciplinarity, globalisation - reveal severe difficulties to describe theoretically the new development, quickly running into problems of complexity of knowledge that limits e.g., possibilities of causal explanation. Outdating and reuse of knowledge and concepts need to be formulated with more criteria for assessment of knowledge. Most of the practical suggestions for knowledge to be included in sustainable resource use are oriented to knowledge practices e.g., in agriculture that appear as premodern. To use 19th-century biology and chemistry in the sustainability discourse would certainly not be an option. However, also after the postmodern interlude it cannot be ignored that many concepts and knowledge components about sustainable resource use have been formulated in prior development phases or historical times, but cannot be replaced easily. Innovation is not simply generated through new research and technologies, also through re-evaluation of older knowledge.

Unsolved problems and dilemmas: Sustainability research and sustainable development are unfolding on unstable ground. Modern societies in the globalisation process have been described as "liquid modernity" (Bauman, taking up ideas earlier found in Luhmanns' theory of modern society). Instability, reflexivity and contingency of social relations may also influence sustainability. However, such diagnoses of postmodernism seem to neglect other important system components and global economic and political power relations. Power relations have not vanished, rather become invisible or latent. Global resource flows organised through market transactions do not show adaptive capacity required for sustainable development to create more equal distribution of resources between men. Sustainable development requires a re-embedding of markets and becomes a complicated, conflicting and contradictory process. It is not possible as homogeneous global economic process, requires continuously following incompatible aims and searching for compromises, but needs to be driven as global discourse. Unexpected and unforeseeable events restrict the time perspective, but at the same time sustainable development requires much longer time perspectives into future than any other policy, planning or resource management strategies hitherto-several generations. The transformation process happens under conditions of globalisation as lifting barriers to global mobility, capital and resource flows, but questions of limiting and changing resource use, production and consumption need to be addressed.

To go further: At present the debate about sustainability has been driven to the point asking, can human wellbeing be maintained over long or infinite time? This happens at the same time when also the debate about unequal exchange [119-121] and global resource flows [122,123] intensifies. 
"Sustainability poses the challenges of determining whether we can hope to see the current level of well-being at least maintained for future periods or future generations, or whether the most likely scenario is that it will decline" [124]. The question covers an inexact diagnosis of the current level of well-being. There is no common current level of well-being, neither in comparing countries, nor within countries, but at both levels a still widening gap between rich minorities and poor majorities. The fictitious "current level of well-being" is formulated ex post, from the amount of resources consumed by global population in a given period of time. It does not allow more than to confirm that most resources are consumed by the minority of rich or industrialized countries - and within a national economy that most resources are consumed by the richer social classes and groups, although there may be a more or less democratically legitimized re-distribution of resources through social policies. There is sufficient reason to continue with the debate.

\section{References}

1. Holling, C.S. Theories for sustainable futures. Conserv. Ecol. 2000, 4, 7.

2. Sneddon, C.; Howarth, R.B.; Norgaard, R.B. Sustainable development in a post-Brundtland world. Ecol. Econ. 2006, 57, 253-268.

3. Young, O.R.; Berkhout, F.; Gallopin, G.C.; Janssen, M.A.; Ostrom, E.; van der Leeuw, S. The globalization of socio-ecological systems: an agenda for scientific research. Global Environ. Change 2006, 16, 304-316.

4. Goodland, R. The concept of environmental sustainability. Annu. Rev. Ecol. Syst. 1995, 26, $1-24$.

5. Norton, B.G. Sustainability: A Philosophy of Adaptive Ecosystem Management; University of Chicago Press: Chicago, IL, USA, 2005; p. 363.

6. Luks, F.; Siemer, S.H. Whither sustainable development? A plea for humility. Gaia 2007, 16, 193-199.

7. Newell, B.; Crumley, C.L.; Hassan, N.; Lambin, E.F.; Pahl-Wostl, C.; Underdal, A.; Wasson, R. A conceptual template for integrative human-environment research. Global Environ. Change 2005, 15, 299-307.

8. Kasenmir, B.; Jaeger, C.; Jäger, J. Citizen participation in sustainability assessments. In Public Participation in Sustainability Science: A Handbook; Kasemir, B., Jäger, J., Jaeger, C., Gardner, M., Eds.; Cambridge University Press: Cambridge, UK, 2003; pp. 3-36.

9. Blackstock, K.L.; Kelly, G.J.; Horsey, B.L. Developing and applying a framework to evaluate participatory research for sustainability. Ecol. Econ. 2007, 60, 726-742.

10. Moffatt, I. Sustainable Development: Principles, Analysis and Policies; The Parthenon Publishing Group: Carnforth, UK, 1995; p. 45.

11. Rao, P.K. Sustainable Development. Economics and Policy; Blackwell Publishers: Oxford, UK, 2000; p. 353.

12. Global Sustainable Development in the 21st Century; Lee, K., Holland, A., McNeill, D., Eds.; Edinburgh University Press: Edinburgh, UK, 2000.

13. Trainer, T. The 'de-materialization' myth. Technol. Soc. 2001, 23, 505-514. 
14. Wiener, A.J. "The 'De-materialization' Myth" and the limits to growth: a commentary on Dr. Trainer's paper. Technol. Soc. 2001, 23, 515-521.

15. Martinez-Alier, J. Ecological distribution conflicts and indicators of sustainability. Int. J. Politi. Econ. 2004, 34, 13-30.

16. Rice, J. Ecological unequal exchange: consumption, equity, and unsustainable structural relationships within the global economy. Int. J. Comp. Sociol. 2007, 48, 43-72.

17. Sorell, S.; Dimitropoulos, J. The rebound effect: microeconomic definitions, limitations and extensions. Ecol. Econ. 2008, 65, 636-649.

18. Wallerstein, I. Las estructuras del conocimiento o? De cuántas maneras podemos conocer? Espacio Abierto 1998, 7, 309-317.

19. Urry, J. Global Complexity; Polity Press: Cambridge, UK, 2003.

20. Urry, J. The complexity turn. Theor. Cult. Soc. 2005, 22, 1-14.

21. Rural Sustainable Development in the Knowledge Society; Bruckmeier, K., Tovey, H., Eds.; Ashgate Press: Surrey, UK, 2009.

22. Appleton, A.F. Sustainability: a practitioner's reflection. Technol. Soc. 2006, 28, 3-18.

23. Manderson, A. A Systems based framework to examine the multi-contextural application of the sustainability concept. Environ. Dev. Sustain. 2006, 8, 85-97.

24. Haraway, D. Situated knowledges: the science question in feminism and the privilege of partial perspective. Feminist. stud. 1988, 14, 575-599.

25. Becker, C.D.; Ostrom, E. Human ecology and resource sustainability: the importance of institutional diversity. Annu. Rev. Ecol. Syst. 1995, 26, 113-133.

26. Ostrom, E. Understanding Institutional Diversity; Princeton University Press: Princeton, NJ, USA, 2005.

27. Martinez-Alier, J. The Environmentalism of the Poor: A Study of Ecological Conflicts and Valuation; Edward Elgar: Cheltenham, UK, 2002.

28. Dauvergne, P. The Shadows of Consumption: Consequences for the Global Environment; MIT Press: Cambridge, MA, USA, 2008.

29. Polanyi, K. The Great Transformation; Rinehart: New York, NY, USA, 1944.

30. Adaman, F.; Devine, P.; Ozkaynak, B. Reinstituting the economic process: (re)embedding the economy in society and nature. Int. Rev. Sociol. 2003, 13, 357-374.

31. McCarthy, D.P. A Critical Systems Approach to Socio-Ecological Systems: Implications for Social Learning and Governance. PhD Thesis, University of Waterloo, Waterloo, Canada, 2006.

32. Vuillemin, J. Nécessité ou Contingence; Les éditions du minuit: Paris, France, 1984.

33. Daniel, U. Kompendium Kulturgeschichte: Theorien, Praxis, Schlüsselwörter, 3rd ed.; Suhrkamp: Frankfurt am Main, Germany, 2004.

34. Boulding, K.E. The epistemology of complex systems. Eur. J. Oper. Res. 1987, 30, 110-116.

35. Agrawal, A. Sustainable governance of common pool resources: context, methods, and politics. Annu. Rev. Anthropol. 2003, 32, 243-262.

36. Acheson, J.M. Institutional failure in resource management. Annu. Rev. Anthropol. 2006, 35, 117-134.

37. Cash, D.W.; Clark, W.C.; Alcock, F.; Dickson, N.M.; Eckley, N.; Guston, D.H.; Jäger, J.; Mitchell, R.B. Knowledge systems for sustainable development. PNAS 2002, 100, 8086-8091. 
38. Vatn, A. Resource regimes and cooperation. Land Use Policy 2007, 24, 624-632.

39. Jansen, M.A.; Anderies, J.M. Robustness and trade-offs in social-ecological systems. Int. J. Common. 2007, 1, 43-65.

40. Rammel, C.; Stagl, S.; Wilfing, H. Managing complex adaptive systems - a co-evolutionary perspective on natural resource management. Ecol. Econ. 2007, 47, 121-133.

41. Escobar, A. After Nature: steps to an antiessentialist political ecology. Curr. Anthropol. 1999, 40, 1-30.

42. Goldman, M.; Schurman, R.A. Closing the 'Great Divide': new social theory on society and nature. Annu. Rev. Sociol. 2000, 26, 563-584.

43. Forsyth, T. Critical Political Ecology: The Politics of Environmental Science; Routledge: London, UK, 2003.

44. Walker, P.A. Political ecology: where is the ecology? Prog. Hum. Geogr. 2005, 29, 73-82.

45. Held, D.; McGrew, A. Globalization Theoy: Approaches and Controversies; Polity Press: Cambridge, UK, 2007.

46. Milner, H.V.; Mukherjee, B. Democratization and Economic globalization. Annu. Rev. Polit. Sci. 2009, 12, 163-181.

47. Nowotny, H.; Scott, P.; Gibbons, M. Re-Thinking Science: Knowledge and the Public in an Age of Uncertainty; Polity Press: Oxford, UK, 2001.

48. Strathern, M. Re-Describing society. Minerva 2003, 42, 263-276.

49. Knorr-Cetina, K. Epistemic Cultures: How the Sciences Make Knowledge; Harvard University Press: Cambridge, MA, USA, 1999.

50. Franklin, S. Science as culture, cultures of science. Annu. Rev. Anthropol. 1995, 24, 163-184.

51. Luhmann, N. Die Soziologie des Wissens: Probleme ihrer theroretischen Konstruktion. In Gesellschaftsstruktur und Semantik; Luhmann, N., Ed.; Suhrkamp: Frankfurt am Main, Germany, 1999; pp. 151-180.

52. Procter, J.D. The social construction of nature: relativist accusations, pragmatist and critical realist responses. Ann. Assn. Amer. Geogr. 1998, 88, 352-376.

53. Jones, S. Social constructionism and the environment: through the quagmire. Global Environ. Change 2002, 12, 247-251.

54. Demeritt, D. What is the 'social construction of nature'? A typology and sympathetic critique. Prog. Hum. Geogr. 2002, 26, 767-790.

55. Ivakhiv, A. Toward a multicultural ecology. Organ. Environ. 2002, 15, 389-409.

56. Asdal, K. The Problematic nature of nature: the post-constructivist challenge to environmental history. Hist. Theory 2003, 42, 60-74.

57. Boron, A. A social theory for the 21 st century? Curr. Sociol. 1999, 47, 47-64.

58. Stehr, N. Wissenspolitik. Die Ûberwachung des Wissens; Suhrkamp: Frankfurt am Main, Germany, 2003.

59. Miller T.R.; Bird, T.D.; Littlefield, C.M.; Kofinas, G.; Chapin, F.S., III; Redman, C.L. Epistemological pluralism: reorganizing interdisciplinary research. Ecol. Soc. 1999, 13, 1-17.

60. Mostovicz, E.I.; Kakabaddse, N.K.; Kakabadse, A.P. Janusian mapping: a mechanism of interpretation. Syst. Pract. Action Res. 2008, 21, 211-225. 
61. Redclift, M. Dances with wolves? Interdisciplinary research on the global environment. Global Environ. Change 1998, 8, 177-182.

62. Davidson, D.J.; Frickel, S. Understanding environmental governance. Organ. Environ. 2004, 17, 471-492.

63. Resilience and the Behavior of Large-Scale Systems; Gunderson, L.H., Pritchard, L., Jr., Eds.; Island Press: Washington, DC, USA, 2002.

64. Navigating Social-Ecological Systems: Building Resilience for Complexity and Change; Berkes, F., Colding, J., Folke, C., Eds.; Cambridge University Press: Cambridge, UK, 2003.

65. Folke, C. Resilience: the emergence of a perspective for social-ecological analyses. Global Environ. Change 2006, 16, 253-267.

66. Perrings, C. Resilience and sustainable development. Environ. Dev. Econ. 2006, 11, 417-427.

67. Scoones, I. New Ecology and the social sciences: what prospects for a fruitful engagement? Annu. Rev. Anthropol. 1999, 28, 479-507.

68. Lawrence, R. Human ecology and its applications for sustainability research. In Handbook of Sustainability Research; Filho, W.L., Ed.; Peter Lang: Frankfurt am Main, Germany; 2005; pp. 121-145.

69. Common, M.; Perrings, C. Towards an ecological economics of sustainability. Ecol. Econ. 1992, 6, 7-34.

70. Saloranta, T.M. Post-Normal science and the global climate change issue. Climatic Change 2001, 50, 395-404.

71. Adger, N. Social and ecological resilience: are they related? Prog. Hum. Geogr. 2000, 24, 347-364.

72. Olsen, M.E. Components of socioecological organization: tools, resources, energy, and power. Adv. Hum. Ecol. 1993, 2, 35-67.

73. Sociological Theory and the Environment: Classical Foundations, Contemporary Insights; Dunlap, R., Buttel, F.H., Dickens, P., Gijswijt, A., Eds.; Rowman \& Littlefield Publishers: Lanham, MD, USA; 2002.

74. Sutton, P.W. Nature, Environment and Society; Palgrave MacMillan: New York, NY, USA, 2004.

75. Haila, I. Beyond the Nature-culture dualism. Biol. Philos. 2000, 15, 155-175.

76. Tapio, P.; Willamo, R. Developing interdisciplinary frameworks. Ambio 2008, 17, 125-133.

77. Szostak, R. Classifying Natural and social scientific theories. Sociology 2003, 51, 27-49.

78. Little, P.E. Environments and environmentalisms in anthropological research: facing a new millennium. Ann. Rev. Anthropol, 1999, 28, 253-284.

79. The Risk Society and beyond: Critical Issues or Social Theory; Adams, B., Beck, U., van Loon, J., Eds.; Sage Publications: Thousand Oaks, CA, USA, 2000.

80. Elliott, A. Becks's sociology of risk: a critical assessment. Sociology 2002, 36, 293-315.

81. Beck, U.; Giddens, A.; Lash, S. Reflexive Modernization: Politics, Traditions and Aesthetics in the Modern Social Order; Polity Press: Cambridge, UK, 1994.

82. Murdoch, J. Ecologising sociology: actor-network theory, co-construction and the problem of human exemptionalism. Sociology 2001, 35, 111-133.

83. Cerulo, K.A. Nonhumans in social interaction. Ann. Rev. Sociol. 2009, 35, 531-552.

84. Meyer, J.W. Globalization: theory and trends. Int. J. Comp. Sociol. 2009, 48, 261-273. 
85. Mol, A.; Spaargaren, G. Ecological modernisation theory in debate: a review. Environ. Polit. 2000, 9, 17-49.

86. Moore, J.W. The modern world system as environmental history? Theory Soc. 2003, 32, 307-377.

87. Rethinking Environmental History: World-System History and Global Environmental Change; Hornborg, A., McNeill, J.R., Martinez-Alier, J., Eds.; Altamira Press: Lanham, UK, 2007.

88. Balée, W. The research program of historical ecology. Ann. Rev. Anthropol. 2006, 35, 75-98.

89. Moscovici, S. Essai sur l'histoire humanine de la nature; Flammarion: Paris, France, 1968.

90. Soziale Ökologie. Grundzüge einer Wissenschaft von den gesellschaftlichen Naturverhältnissen; Becker, E., Jahn, T., Eds.; Campus: Frankfurt am Main, Germany, 2006.

91. Weisz, H. Gesellschaft-Natur Koevolution: Bedingungen der Möglichkeit nachhaltiger Entwicklung; Humboldt-Universität: Berlin, Germany, 2002; Available online: http://edoc.huberlin.de/dissertationen/weisz-helga-2002-03-21/PDF/Weisz.pdf (accessed on 30 October 2009).

92. Socioecological Transitions and Global Change. Trajectories of Social Metabolism and Land Use; Fischer-Kowalski, M., Haberl, H., Eds.; Edward Elgar: Cheltenham, UK, 2007.

93. Fischer-Kowalski, M.; Haberl, H. Sustainable development: socio-economic metabolism and colonization of nature. Int. Soc. Sci. J. 1998, 158, 573-587.

94. Brand, U.; Brunnengräber, A.; Schrader, L.; Stock, C.; Wahl, P. Global Governance: Alternative zur neoliberalen Globalisierung? Westfälisches Dampfboot: Münster, Germany, 2000.

95. Ludwig, D. The era of management is over. Ecosystems 2001, 4, 758-764.

96. Pascual, M.; Guichard, F. Criticality and disturbance in spatial ecological systems. Trend. Ecol. Evolut. 2004, 20, 88-95.

97. Lansing, S.J. Complex adaptive systems. Annu. Rev. Anthropol. 2003, 32, 83-204.

98. Hirsch Hadorn, G.; Bradley, D.; Pohl, C.; Rist, S.; Wiesmann, U. Implications of transdisciplinarity for sustainability research. Ecol. Econ. 2006, 60, 119-128.

99. Longino, H. The Fate of Knowledge; Princeton University Press: Princeton, NJ, USA, 2002.

100. Leydesdorff, L. The Triple helix model and the study of knowledge-based innovation systems. Int. J. Contemp. Sociol. 2005, 42, 1-16.

101. Bauman Z. Ansichten der Postmoderne; Argument-Verlag: Hamburg und Berlin, Germany, 1995.

102. Funtowicz, S.; Ravetz, J. Science for the post-normal age. Futures 1993, 25, 735-755.

103. Ravetz, J. What is post-normal science? Futures 1999, 31, 647-654.

104. Gallopin, G.C.; Funtowics, S.; O’Connor, M.; Ravetz, J. Science for the 21st century: from social contract to the scientific core. Int. J. Soc. Sci. 2001, 168, 219-229.

105. Ravetz, J. Science and sustainability. In Science and Technology Policies in Europe: New Challenges and New Responses, Proceedings of the STRATA Consolidating Workshop, Brussels, Belgium, April, 2002; pp. 162-193.

106. Daly, H.E.; Townsend, K.N. Valuing the Earth: Economics, Ecology, Ethics; MIT Press: Cambridge, MA, USA, 1993.

107. Böhringer, C.; Jochem, P.E.P. Measuring the immeasurable: a survey of sustainability indices. Ecol. Econ. 2007, 63, 1-8. 
108. Ness, B.; Urbel-Piirsalu, E.; Anderberg, S.; Olsson, L. Categorising tools for sustainability assessment. Ecol. Econ. 2007, 60, 498-508.

109. Wackernagel, M.; Schulz, N.B.; Deumling, D.; Callejas Linares, A.; Jenkins, M.; Kapos, V.; Monfreda, C.; Loh, J.; Myers, N.; Norgaard, R.; Randers, J. Tracking the ecological overshoot of the human economy. PNAS 2002, 99, 9266-9271.

110. Moran, D.; Wackernagel, M.; Kitzes, J.A.; Goldfinger, S.H.; Boutand, A. Measuring sustainable development — nation by nation. Ecol. Econ. 2008, 64, 470-474.

111. Weisz, H.; Krausmann, F.; Amann, C.; Eisenmenger, N.; Erb, K.-H.; Hubaeck, K.; Fischer-Kowalski, M. The physical economy of the European Union: cross-country comparison and determinants of material consumption. Ecol. Econ. 2006, 58, 676-698.

112. Haberl, H.; Fischer-Kowalski, M.; Krausmann, F.; Weisz, H.; Winiwarter, V. Progress towards sustainability? What the conceptual framework of material and energy flow accounting (MEFA) can offer. Land Use Policy 2007, 21, 199-213.

113. Haberl, H.; Erb, K.-H.; Krausmann, F.; McGinley, M. Global appropriation of net primary production (HANPP). In Encyclopedia of Earth; Environmental Information Coalition, National Council for Science and the Environment: Washington, DC, USA, 2008; Available online: http://www.eoartharth.org/article/Global_human_approriation_of_net_primary_production_(HA $\mathrm{NPP}=$ ) (accessed on 30 October 2009).

114. Wherry, F. International statistics and social structure: the case of the human development index. Int. Rev. Sociol. 2004, 14, 151-169.

115. Siche, J.R.; Agostinho, F.; Ortega, E.; Romeiro, A. Sustainability of nations by indices: comparative study between environmental sustainability index, ecological footprint and the emergy performance indices. Ecol. Econ. 2008, 66, 628-637.

116. Hukkinen, J. From groundless universalism to grounded generalism: improving ecological economic indicators of human-environmental interaction. Ecol. Econ. 2003, 44, 11-27.

117. Vickers, J.M. Objectivity and Ideology in the human sciences. Topoi 1991, 10, 175-186.

118. Keil, F.; Stiess, I. Wissen, was wir nicht wissen: Umweltforschung als gesellschaftlicher Lernprozess. GAIA 2007, 16, 193-199.

119. Rice, J. The transnational organization of production and uneven environmental degradation and change in the world economy. Int. J. Comp. Sociol. 2009, 50, 215-236.

120. Jorgensen, A.K.; Austin, K.; Dick, C. Ecologically unequal exchange and the resource consumption/environmental degradation paradox. Int. J. Comp. Sociol. 2009, 50, 263-284.

121. Lawrence, K.S. The thermodynamics of unequal exchange. Int. J. Comp. Sociol. 2009, 50, 335-359.

122. Krausmann, F.; Gingrich, S.; Eisenmenger, N.; Erb, K.-H.; Haberl, H.; Fischer-Kowalski, M. Growth in global materials use, GDP and population during the 20th century. Ecol. Econ. 2009, 68, 2696-2705.

123. Schandl, H.; Fischer-Kowalski, M.; Grunbuhel, C.; Krausmann, F. Socio-metabolic transitions in developing Asia. Technol. Forecast. Soc. Change 2009, 76, 267-281. 
124. Stiglitz, J.E.; Sen, A.; Fitoussi, J.-P. Report by the Commission on the Measurement of Economic Performance and Social Progress; p. 61; Available online: www.stiglitz-sen-fitoussi.fr (accessed on 30 October 2009).

(C) 2009 by the authors; licensee Molecular Diversity Preservation International, Basel, Switzerland. This article is an open-access article distributed under the terms and conditions of the Creative Commons Attribution license (http://creativecommons.org/licenses/by/3.0/). 